\title{
The ambulance services in northern Norway 2004-2008: improved competence, more tasks, better logistics and increased costs
}

\author{
Jan Norum • Trond M. Elsbak
}

Received: 31 October 2009 /Accepted: 22 January 2010/Published online: 10 April 2010

(C) Springer-Verlag London Ltd 2010

\begin{abstract}
Background The ambulance services in northern Norway have undergone significant development during recent years.

Aims The objective of this study was to describe these changes in terms of tasks performed, distance driven, resources spent and level of competence in terms of education.

Methods A retrospective analysis was performed. The ambulance fleet's activity during the time period 20042008 was analysed. The subject was the ambulance fleet in northern Norway and its crew members. Tasks done, kilometres driven, resources spent per thousand inhabitants and level of competence were the main outcome measures. Results The major findings were almost doubled costs $(92 \%)$, increasing number of tasks performed $(13 \%)$ and a stable situation concerning kilometres driven. We also revealed improving competence in terms of education. A $20 \%$ absolute increase in crew members having a certificate of competence (fagbrev) was observed.
\end{abstract}

The views expressed in this paper are those of the author(s) and not those of the editors, editorial board or publisher.

J. Norum $(\bowtie)$

Department of Clinical Medicine, Faculty of Health Sciences,

University of Tromsø,

9037 Tromsø, Norway

e-mail: jan.norum@helse-nord.no

J. Norum

Department of Oncology, University Hospital of North Norway,

9038 Tromsø, Norway

J. Norum • T. M. Elsbak

Northern Norway Regional Health Authority,

8038 Bodø, Norway
Conclusions Significant economic resources have been invested in the fleet. Improved level of competence and an upgraded coordination system have improved logistics and hopefully treatment outcome. The latter should be further elucidated when the electronic patient record (EPR) system has been implemented.

Keywords Ambulance fleet - Norway - Cost . Competence . Activity

\section{Introduction}

Northern Norway covers half of Norway's land area and constitutes about two thirds of the size of the UK. It has a scattered population of about 470,000 inhabitants and the main industry is fishery. There are 88 municipalities in the region and almost half (42 municipalities) of them have less than 2,000 inhabitants. The significant distances between the populated areas have been a constant challenge to the health care service in terms of costs and logistics. In 2008, the Northern Norway Regional Health Authority (NNRHA) spent Norwegian krone (NKr) 616 million (70 million $€$ ) on patient transportation and NKr 943 million (106 million $€$ ) on ambulance services (air, sea and land). The ambulance services accounted for $8.2 \%$ of the total budget of the NNRHA in 2008 and this service experienced faster growth in terms of resources consumed than any of the other sectors.

Aiming to improve the ambulance service in Norway, the national authorities introduced in 1996 the certificate of competence in prehospital care named fagbrev. The education consists of 2 years in college followed by 2 years of practice at a hospital ambulance service and finally the candidates have to pass an exam. Persons who have been 
working in the ambulance services for at least 5 years may follow a "fast track programme" of 1 year and then head for the exam. In general almost $90 \%$ pass the exam at first attempt.

During the last 5 years, the ambulance services within northern Norway have undergone several reforms. In 2004, the administration of the service was mainly provided by "one-man firms" having contracts with any of the three county councils (Finnmark, Troms, Nordland). New guidelines were implemented in 2005 aiming to standardize the service offered. Furthermore, the ownership of the ambulances was taken over by the NNRHA in 2007 and it has since been administered by the four hospital trusts (Finnmark Hospital Trust, University Hospital of North Norway Trust, Nordland Hospital Trust, Helgeland Hospital Trust). The trusts have since focused on upgrading both crew and equipment. Several crew members have been offered scholarships to get the certificate of competence (fagbrev). The overall goal has been a steadily improving service. Today ECGs can be communicated digitally from the ambulances to the hospitals and prehospital thrombolytic therapy can be administered by the crew when myocardial infarction has been diagnosed. Furthermore, the personnel have participated in continuous internal educational programmes and old ambulances have been exchanged for new ones. The hospital trusts have laid the groundwork for a modern coordination and location system for the entire ambulance fleet by installing a global positioning system (GPS) in all cars.
Several local councils have joined their casualty clinics during the last few years. Consequently, the lower number of clinics has increased the distance to travel. Against this background, the NNRHA initiated in March 2009 a retrospective analysis of this service.

\section{Methods}

Northern Norway has a subarctic climate that may offer several challenges especially during winter time with cold weather conditions, seasonable darkness and a lot of snow. Despite this "back cloth" the population expects a service of equal quality as provided in the southern and more populated regions. In this study, we focused on the total ambulance fleet service in northern Norway and focused on location, activity, crew and level of competence in terms of education. Air and boat ambulances were excluded from the survey.

A geographic overview of northern Norway and its three counties is shown in Fig. 1. In April 2009, the data on activity performed by the ambulance fleet in northern Norway was retrospectively analysed focusing on the 5-year time period from 1 January 2004 until 31 December 2008. The following data on ambulances, crew members and each location were collected:

- Data on each operative ambulance (based on its ID) was noted according to location, trust owner, whether it was in use or in reserve and its daily operative hours.

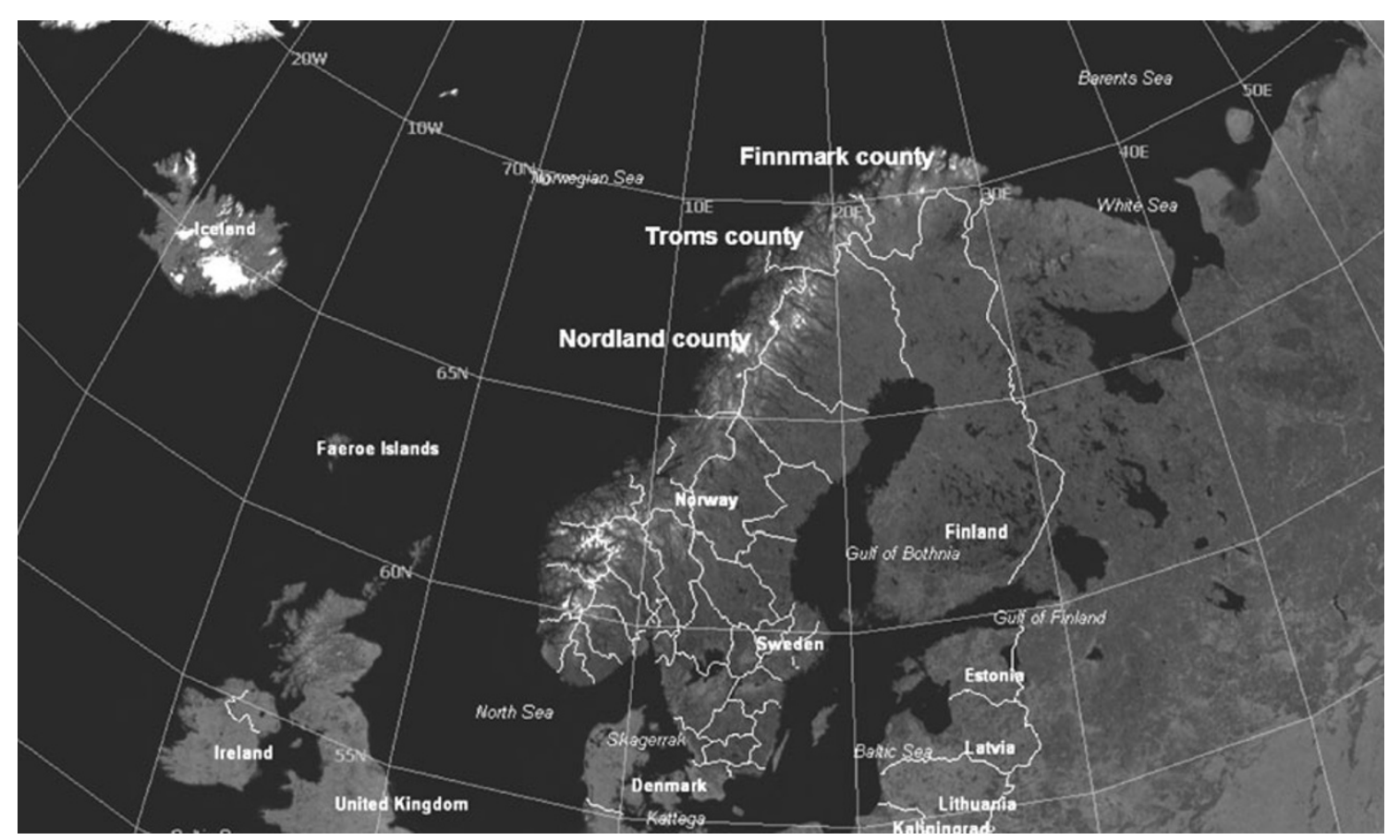

Fig. 1 Map showing the three counties of northern Norway (Nordland, Troms and Finnmark) and the significant land area they cover 
Table 1 Activity measured in number of tasks handled by the ambulance fleet in northern Norway

\begin{tabular}{llllll}
\hline Trust & 2004 & 2005 & 2006 & 2007 & 2008 \\
\hline University Hospital & 23,172 & 24,336 & 25,392 & 26,398 & 27,387 \\
Nordland Hospital & 17,236 & 18,693 & 18,956 & 19,360 & 19,038 \\
Helgeland Hospital & 10,171 & 11,305 & 10,871 & 11,401 & 10,731 \\
Finnmark Hospital & 12,530 & 12,418 & 13,067 & 14,001 & 14,307 \\
Total & 63,109 & 66,752 & 68,286 & 71,160 & 71,463 \\
\hline
\end{tabular}

- Data on crew members were registered in terms of numbers at each location, their state of readiness (five levels: from at home to in active service at the station $24 \mathrm{~h}$ a day), manning and level of competence in terms of education (certificate of competence in prehospital care-fagbrev).

- At each location we registered the annual number of tasks performed, kilometres driven and running expenses. The number of inhabitants in the area served according to Statistics Norway (www.ssb.no) and the distance to the nearest somatic hospital were also noted.

Statistical analysis

The Microsoft Excel 2002 version was employed for the calculations and final database. Descriptive statistics was used. The Statistical Package for the Social Sciences (SPSS) version 16.0 was employed for statistical calculations. Cases with an unknown value for a particular variable were excluded from analysis involving that variable. Statistical analyses were performed by bivariate correlation analysis with Pearson's correlation coefficient. All $P$ values are two tailed and considered statistically significant when $P<0.05$.

Costs were calculated in $\mathrm{Nkr}$ and converted into $€$ at a rate of $1 €=N k r 8.8600$ as of 24 July 2009 according to the national bank (Norges Bank) (www.norges-bank.no).

\section{Results}

There were a total of 124 ambulance units and 6 reserve units distributed in 84 locations; 109 units (88\%) were manned day and night and the figures were constant during the study period. The numbers of full-time posts were University Hospital Trust 255, Nordland Hospital Trust 156, Helgeland Hospital Trust 90 and Finnmark Hospital Trust 151, respectively.

During the 5-year study period, the total number of tasks performed in the region rose by $13 \%$ from 63,109 to 71,463 tasks. The mean number per ambulance in 2008 was 576 tasks. Whereas a slightly falling trend was seen in Nordland county (Nordland Hospital Trust and Helgeland Hospital
Trust) following the takeover by the NNRHA, the figures in the other districts were still rising. Especially the steadily rising trend at the University Hospital Trust was notable. Details can be seen in Table 1 .

Looking at the number of kilometres driven by the fleet, there was (except for Finnmark Hospital Trust) a stable situation with a slightly falling trend after the takeover by the NNRHA in 2007. Details can be seen in Fig. 2. This study was not designed to address causation of this trend, but we would like to mention that in 2007 we started the introduction of a fleet administration and coordination system. The mean distance driven by each car annually was $44,524 \mathrm{~km}$, indicating that the cars are undergoing significant wear and tear. The figure illustrates the significant distances in our region and in particular the situation in the county of Finnmark. In this district, the mean travelling distance per task $(99.8 \mathrm{~km})$ was $30-50 \%$ above the figures at the other trusts. Correlating for the number of tasks and the population (per 1,000 inhabitants), we discovered a very similar pattern in all trusts, except for Finnmark Hospital Trust (26\% higher). Details can be seen in Fig. 3. Not surprisingly, the population of the municipalities was correlated with distance travelled $(P=0.016)$ and number of duties performed $(P=0.021)$.

The number of employees in northern Norway having a fagbrev rose by $20 \%$ (from 38 to $58 \%$ ) during the study period. However, we are still behind the goal of $75 \%$.

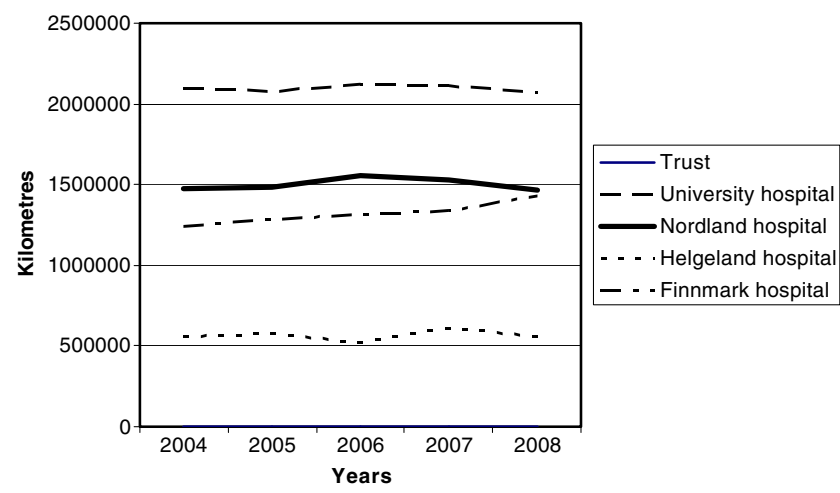

Fig. 2 Number of kilometres driven by the ambulance fleet in the four hospital trusts in northern Norway during the 5-year period 2004-2008 


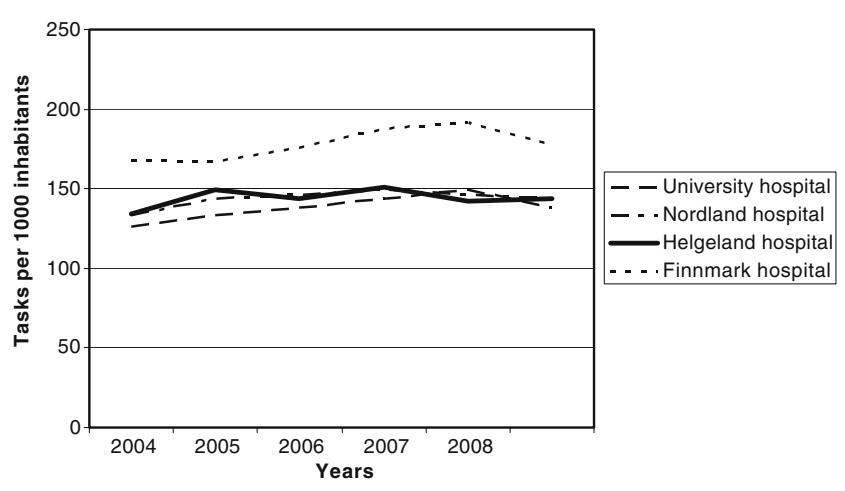

Fig. 3 Number of tasks done by the ambulance service in each hospital trust in northern Norway related to inhabitants (per 1,000 inhabitants) in the area

Focusing on the costs, there has been an increase in the running costs of the ambulance service of $92.3 \%$ during the study period. Most of these expenses were due to persistent upgrade of the service and consequently lasting operating costs at a higher level. During the 5-year time period, the total expenses of the NNRHA rose by $32.7 \%$ (from Nkr $8,690,247$ to $\mathrm{Nkr} 11,535,340)(980,841 €$ to $1,301,957 €)$, strongly indicating that significant resources have been allocated to the ambulance services. The University Hospital of North Norway Trust had the fastest rising costs and the most expensive service. Their cost per ambulance was $47 \%$ higher than the others. During the study period, the cost per ambulance unit increased by $83-132 \%$ depending on hospital trust. The running expenses at each hospital trust are shown in Table 2. In comparison, the price index in Norway rose by $10.7 \%$ from January 2004 to December 2008 (www.ssb.no).

The ambulance fleet did not have any electronic patient record (EPR) system and medical data on patients transported could not be analysed.

\section{Discussion}

The running cost of the ambulance fleet in northern Norway has almost doubled during the study period.
Whereas an increasing number of tasks have been performed, the number of kilometres driven has been stable. The level of competence among workers was significantly improved.

We have analysed the 5-year data on personnel resources and ambulance operations and focused on trends, kilometres driven and level of competence. However, we had no access to data on patients being transported and the quality of the medical service offered to them. Furthermore, we did not include air or boat ambulances. When the ambulance fleet in the near future will be equipped with an EPR system, data on patient care and administration while onboard can be analysed.

The slight drop in number of kilometres driven at the end of the study period may be partly due to a campaign on correct use of transportation (public transportation and taxi when appropriate). Another explanation may be the introduction of the TransMed/TransMobil fleet coordination system and consequently improved logistics. The latter is in accordance with the study by Ong et al. [1] who analysed ambulance calls in Singapore. They reported that the utility of geographic information systems (GIS) had significant implications for maximizing the effectiveness of ambulance deployment. Schuessler and Cotter [2] also concluded that an effective strategic plan for the area of operations must be in place to provide a cost-effective service. This was also elucidated by Dean [3] who concluded that computer-aided dispatch (CAD) systems capable of tracking unit locations outside of their stations were to be recommended.

Finnmark Hospital Trust was the last one implementing our administration and coordination system. This may have caused the lack of any measurable effect on kilometres driven in this area. Furthermore, they had limited access to air ambulances in late 2008 due to new European regulations concerning the staffs' working time. These regulations caused a temporary lack of pilots.

The numbers of ambulance tasks are 36\% higher in northern Norway than in the other regions (central, western, southeast). This may be due to the distinctive characteristics of the northern region. In populated areas in southern Norway, busses with beds are employed. Air and boat
Table 2 Running expenses at each hospital trust in total cost and cost per ambulance unit

The costs are in $1000 €$. The cost per unit varies significantly

\begin{tabular}{llllll}
\hline Hospital trust & 2004 & 2005 & 2006 & 2007 & 2008 \\
\hline University Hospital & 14,113 & 14,496 & 17,345 & 27,978 & 30,152 \\
Per unit & 332 & 341 & 408 & 658 & 710 \\
Nordland Hospital & 8,188 & 8,053 & 9,236 & 13,403 & 14,304 \\
Per unit & 278 & 273 & 313 & 454 & 485 \\
Helgeland Hospital & 4,100 & 4,753 & 5,710 & 7,693 & 8,256 \\
Per unit & 256 & 297 & 357 & 481 & 516 \\
Finnmark Hospital & 7,321 & 7,175 & 7,422 & 9,506 & 12,784 \\
Per unit & 257 & 252 & 260 & 334 & 449 \\
\hline
\end{tabular}


ambulances are more frequently employed in our region and cause a need for an ambulance "at both ends". An increasing number of communities in northern Norway are arranging common casualty clinics causing an increased distance of transportation. In the future it should be discussed whether the cost of a steadily increasing number of ambulance services offered to intercommunity common casualty clinics should be taken care of by the hospital trusts or these clinics themselves.

Life-saving prehospital interventions are one of the main reasons for a steady upgrade of the crew. However, lifesaving operations are rare. A Danish study [4] has documented that only $4 \%$ of patient contacts were lifesaving and most of them were related to opioid poisoning and cardiac arrest. In April 2010, new European regulations will be introduced where every ambulance must be manned by at least one employee with a fagbrev. This indicates that significant effort still has to be put into educational programmes. Whereas the ambulance workers' competence has been improved, a recent study revealed that only $19 \%$ of them reported their competence being appreciated by cooperating medical staff [5]. We have invested in education and consequently improved the salary among workers hoping for an improved service. Whyte and Ansley [6] evaluated a system of financial reward for emergency medical technicians who met selected quality marker goals. Following the incentive, reports were completed within $3 \mathrm{~h}$ $99.7 \%$ of the time (64\% prior to incentive). Aspirin use in adult non-traumatic chest pain improved from 60 to $96.3 \%$ and ECG performance in this group improved from 43 to $87.8 \%$. Documentation of the time of onset of symptoms in stroke patients improved from 97 to $100 \%$, and the assessment of and intervention for pain in traumatic hip pain patients improved from 56 to $100 \%$.

According to today's trend, the population of Norway is aging and one third will be above the age of 67 years in 2030 . This indicates a rising need for ambulance services as the elderly are more often transported by ambulance [7]. Kawakami and co-workers [8] reported that elderly, male, low household income and no possession of a car were all factors causing an increase in the use of ambulances in nonemergency situations. These four factors together potentially produced $16.8-19.2 \%$ of all incremental demands, depending on scenario selected.

One way of keeping the costs down may be reinstallation of the family physician as the important gatekeeper. This is especially important in less populated areas. Beillon and co-workers [9] have documented variations between less and more densely populated Swedish areas with the former having a more appropriate use. Jacob and colleagues [7] asked whether the treating physician agreed with the patient's decision on transport method. There was agreement in $68 \%$ of ambulance transports and $92 \%$ of non-ambulance trans- ports. This indicated that there were few "unmet needs" but some "inappropriate use" in Pennsylvania.

We have indicated that logistic systems can improve the effectiveness of the service. Davis and co-workers [10] employed industrial engineering techniques in the evaluation of the efficiency and effectiveness of the services. By such means, they showed that by a reduction of the number of service units during time of least demand and combining some jobs, money could be saved without affecting the level of service. A similar system streamlining care has been described by Su and Shih in Taiwan [11].

When EPR systems have been installed, further analysis on quality of care should be done and air and boat ambulances included. Today, we hope that an improved level of competence causes medics to do the right things and do them well. However, at present we can document the improved results of the "whole treatment chain", but not the specific contribution by the medics. This may be possible when the EPR has been implemented.

Computer-based ambulance fleet coordination systems may cause reduction in distance travelled and consequently savings, but cost-effectiveness analyses should be performed.

\section{Conclusion}

Significant economic resources have been invested in the ambulance fleet in northern Norway. Improved level of competence and an upgraded coordination system have improved logistics and hopefully treatment outcome. The latter should be further elucidated when the EPR system has been implemented.

Acknowledgements We wish to thank the personnel at the emergency departments and ambulance locations for their cooperation.

Funding The study was funded by the North Norway Regional Health Authority.

Conflicts of interest None.

\section{References}

1. Ong ME, Ng FS, Overton J, Yap S, Andresen D, Yong DK, Lim SH, Anantharaman V (2009) Geographic-time distribution of ambulance calls in Singapore: utility of geographic information system in ambulance deployment (CARE 3). Ann Acad Med Singapore 38(3): 184-191

2. Schuessler G, Cotter S (2008) Ready to roll. EMS Mag 37(6):78-82

3. Dean SF (2008) Why the closest ambulance cannot be dispatched in an urban emergency medical services system. Prehosp Disaster Med 23(2):161-165 
4. Ramberg E, Skak C, Nielsen SL, Rasmussen LS (2009) Lifesaving prehospital interventions (in Danish). Ugeskr Laeger 171 (3): 134-137

5. Førland O, Zakariassen E, Hunskår S (2009) Cooperation between ambulance personnel and regular general practitioners (in Norwegian). Tidsskr Nor Laegeforen 129(11):1109-1111

6. Whyte BS, Ansley R (2008) Pay for performance improves rural EMS quality: investment in prehospital care. Prehosp Emerg Care 12(4):495-497

7. Jacob SL, Jacoby J, Heller SJ, Stoltzfus J (2008) Patient and physician perspectives on ambulance utilization. Prehosp Emerg Care 12(2):176-181

8. Kawakami C, Ohshige K, Kubota K, Tochikubo O (2007) Influence of socioeconomic factors on medically unnecessary ambulance calls. BMC Health Serv Res 7:120-128
9. Beillon LM, Suserud BO, Karlberg I, Herlitz J (2009) Does ambulance use differ between geographic areas? A survey of ambulance use in sparsely and densely populated areas. Am J Emerg Med 27(2):202-211

10. Davis J, Kuhns R, Watson DJ (2004) Evaluating emergency medical services: controlling the rising cost of saving lives. J Health Hum Serv Adm 26(4):485-512

11. Su S, Shih CL (2003) Modeling an emergency medical services system using computer simulation. Int J Med Inform 72(1-3):57-72

Jan Norum is a medical oncologist, professor at the Faculty of Medicine at the University of Troms $\varnothing$ and medical director at the North Norway Regional Health Authority. 